\title{
An experimental animal model of granulomatous bowel disease
}

\author{
I C MITCHELL AND J L TURK \\ From the Royal College of Surgeons of England, Lincoln's Inn Fields, London
}

\begin{abstract}
SUMmARY A study has been undertaken of the granulomatous response induced in the ascending colon and terminal ileum of the guinea pig by the direct inoculation of mycobacterial antigens. Live BCG (Pasteur) $2 \times 10^{7}$ at two weeks induced epithelioid cell granulomas in both large and small bowel and in the draining lymph nodes. The area of infiltration was significantly greater for a given inoculum in the large bowel. Acid fast bacilli were present on Ziehl Neelson stained sections of the large bowel infiltrate, but only rarely in sections from the small bowel lesions. The response to skin testing with a standardised amount of purified protein derivative was less in animals inoculated in the small bowel. Inoculation with $2 \times 10^{9}$ cobalt irradiated BCG gave rise, at five weeks, to granulomas containing lesser numbers of epithelioid cells and caseation was sometimes evident. There was a similar but smaller difference in the degree of infiltration at the two inoculation sites. Ziehl Neelson staining failed to reveal the presence of acid fast bacilli in any sections of the bowel infiltrates. Skin testing with purified protein derivative gave a response which was greater in animals inoculated in the small bowel. An identical dose of Cobalt irradiated $M$ leprae induced at five weeks a predominantly macrophage granuloma in both the large and small bowel, with no significant difference in the degree of infiltration at the two sites. No acid fast bacilli were seen in Ziehl Neelson stained sections of the bowel and skin testing with purified protein derivative was reduced These findings and their relevance to studies of the aetiology of Crohn's disease are discussed.
\end{abstract}

There have been many attempts to produce an animal model of inflammatory bowel disease (IBD) using a variety of mineral or biological reagents. ${ }^{1-3}$ Work in the $1970 \mathrm{~s}^{4}$ using homogenates of human Crohn's disease tissue inoculated into the ileum of rabbits showed, over a prolonged period in some cases, the development of granulomatous changes in the bowel wall. Subsequent efforts to repeat this work have met with mixed success. ${ }^{56}$

More recently ${ }^{7}$ an organism belonging to the Runyon group 111 mycobacteria, perhaps most closely related to Mycobacterium paratuberculosis was isolated after prolonged culture from resected bowel tissue of a patient with Crohn's disease. Other workers have described the isolation of a variety of

Address for correspondence: Mr I C Mitchell, Department of Pathology, Royal College of Surgeons of England, 35-43 Lincoln's Inn Fields, London WC2A 3PN

Accepted for publication 12 May 1989. cell wall deficient forms of mycobacteria from tissue of patients with Crohn's disease ${ }^{89}$ No information is, however, available on the effect of the direct inoculation of mycobacteria into the bowel wall. Thus it was considered of interest to ascertain these responses and to compare them with those known to result from the inoculation of mycobacteria into the peripheral tissues of animals of the same strain and sex..$^{10}$ i1 Two different mycobacteria were used: BCG which produced a predominantly epithelioid cell granuloma (Fig. 1) and Mycobacterium leprae which in the guinea pig produced a predominantly macrophage type granuloma. ${ }^{10}$

\section{Methods}

ANIMALS

Outbred Hartley strain female guinea pigs weighing 280-340 g were used. They were fed on an RGP pelleted diet supplemented with cabbage. 


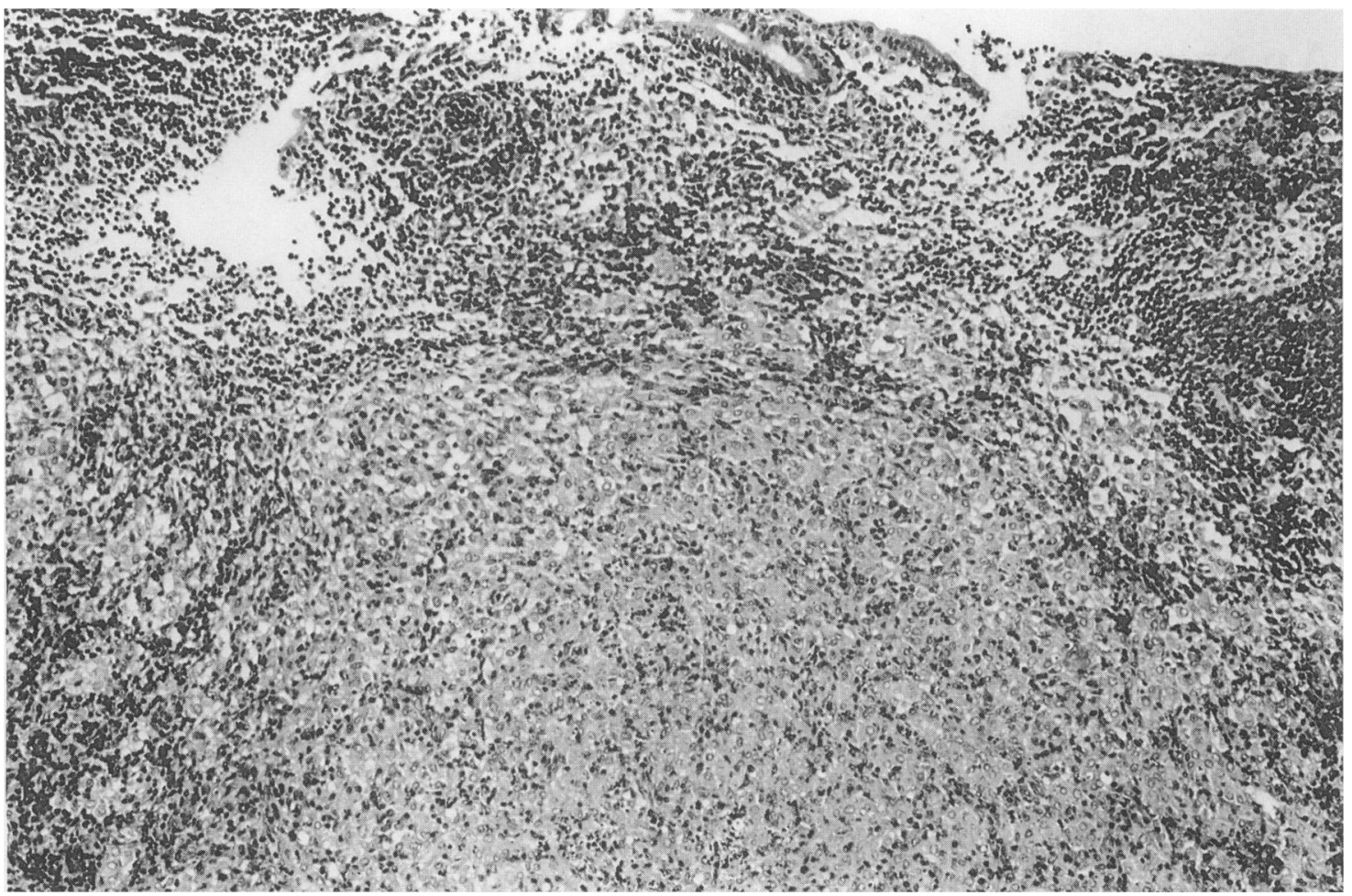

Fig. 1 Granulomatous infiltration of terminal ileum two weeks after inoculation with live BCG (Pasteur). Haematoxylin and eosin. $\times 70$.

MYCOBACTERIA

Live BCG was of Pasteur strain obtained by courtesy of the Institut Pasteur, Paris. Cobalt irradiated armadillo derived Mycobacterium leprae and cobalt irradiation of BCG (Pasteur), was provided courtesy of Dr R J W Rees, National Institute for Medical Research, Mill Hill, London. The mycobacteria were obtained as a suspension in saline. The BCG organisms were counted by the method of Miles and Misra $^{12}$ for viable organisms. M Leprae were counted by the method of Hart and Rees ${ }^{13}$ which gives a count of the total number of intact organisms. Live $M$ Leprae was not used because of legal restrictions owing to its pathogenicity in man.

L. A PAROTOMY

Guinea pigs were anaesthetised with intramuscular neuroleptanalgesia using a combination of Hypnorm (Janssen Pharmaceuticals Ltd) and Hypnoval (Roche Products Ltd). The abdomen was shaved and the skin cleansed with $70 \%$ alcohol. A sterile drape with a central aperture was secured in position with an Opsite dressing (Smith \& Nephew Medical Ltd). A $3 \mathrm{~cm}$ lower abdominal midline incision was made to the peritoneum which was lifted free of the abdominal contents with non-toothed forceps and incised. The edges of the wound were grasped with Poirers tissue forceps and reflected. This approach gave ready access to the inoculation sites in the terminal ileum and the ascending colon. After inoculation (see below) the bowel was returned to the abdomen and the muscle layer closed carefully with a continuous 3:0 Vicryl suture (Ethicon Ltd, UK). The skin was closed with 4:0 interrupted Vicryl sutures. The sutures were reinforced using Histoacryl Tissuc Adhesive (B Braun Melsungen AG, West Germany).

INOCULATION

All inoculations were of $50 \mu \mathrm{l}$ and standard doses of organisms $\left(2 \times 10^{7} \mathrm{BCG}, 2 \times 10^{4}\right.$ irradiated BCG, and $2 \times 10^{4}$ irradiated $M$ leprae) were used. Inoculation was performed, using a Hamilton microlitre syringe and a $32 \mathrm{G}$ needle, into the serosa of the antemesenteric wall of the bowel at the level of either the most distal terminal ileal Peyer's patch or the most proximal Peyer's patch of the ascending colon. The doses used were based upon earlier work" "I which had produced a satisfactory response in the posterior 
auricular lymph node of the guinea pig, maximal at two and five weeks respectively. They have also been shown to induce sensitivity to $25 \mu \mathrm{g}$ Purified Protein Derivative (PPD) of tuberculin on skin testing. "' " 114 This dose produces no response in unsensitised guinea pigs.

\section{CONTROLS}

Control animals were inoculated identically with the same volume of physiological saline.

\section{SKIN TESTS}

Twenty four hours before harvesting the right flank of each animal was shaved and an injection of $25 \mu \mathrm{g}$ dialysed purified protein derivative in a volume of $0 \cdot 1$ $\mathrm{ml}$ was injected intradermally. The delayed hypersensitivity reaction was read at 24 hours using Schnelltäster Kröplin callipers A $02 \mathrm{~T}$ to measure the increase in skinfold thickness. The results are expressed as specific increases in skin thickness, which represent the reading $(10$-imm) at the skin test site, minus the average thickness of the normal skin on both sides of the site.

\section{HARVESTING}

After terminal anaesthesia the abdomen was reopened through the original incision. After a general examination of the abdominal contents, the inoculated area of bowel was excised, trimmed and placed in $10 \%$ formal saline as were representative samples of liver and spleen. The ileocolic and caecal lymph nodes, which drain primarily the ascending colon and terminal ileum respectively, were excised, weighed and prepared for fixation in Carnoy's solution. Samples of representative specimens were taken for electron microscopy. These were cut into very fine pieces, fixed in $4 \%$ glutaraldehyde for 24 hours at $4^{\circ} \mathrm{C}$ and then transferred to $0.05 \%$ cacodylate buffer before further processing.

Specimens for light microscopy were processed in a standard manner, embedded in wax and representative $5 \mu \mathrm{m}$ sections cut. Sequential sections were stained with haematoxylin and eosin (H\&E) and Ziehl Neelson (ZN) stains. The coded sections were read by the same observer (ICM) and demarcated as 'negative' or 'positive' depending upon the presence of granulomas on H\&E staining. The presence or absence of ulceration and its site was also noted in the bowel specimens. If granulomatous infiltration was present then its extent was measured using a projection microscope and planimeter.

In the case of the lymph node, the areas of infiltration and the total area of the section, were traced on to a white sheet from the projected image ( $\times 36$ magnification). The total area of the section and the infiltrated areas were measured using a fixed arm planimeter $\left(1 \mathrm{rev}=100 \mathrm{~cm}^{2} ;\right.$ constant $\left.=18728\right)$ and the area of infiltration expressed as a percentage of the total area. In the case of the bowel sections, a similar procedure was followed, but a single representative field containing the inoculation site, together with all the granulomatous infiltration, was chosen and measured in an identical manner. Statistical assessment of data was by the Student's $t$ test. All Ziehl Neelson sections were scanned completely and the presence or absence of acid fast bacilli noted.

\section{Results}

CIIINICAL OBSERVATION

Animals in all the experiments were observed on a daily basis. They all gained weight normally and none showed any signs of clinical disease.

\section{SKIN TESTS}

These findings are given in Table 1. Inoculation with live BCG in either the terminal ileum or ascending colon, induced a significant reaction to purified protein derivative at two weeks $\mathrm{p}<0.002$ and $\mathrm{p}<0 \cdot 001$ respectively. The response was greater after inoculation in the ascending colon although this difference did not reach a significant level. Animals inoculated in the terminal ileum also showed a further enhancement of response at five weeks but on analysis this increase was not found to be significant.

Table 1 Skin reaction to $25 \mu \mathrm{g}$ of intradermal (purified protein derivative) after 24 hours expressed as increase in skinfold thickness mm-l (SD)

\begin{tabular}{|c|c|}
\hline & $\begin{array}{l}\text { Increase in } \\
\text { skinfold thickness } \\
(\mathrm{mm})\end{array}$ \\
\hline $\mathrm{BCG}$ in ascending colon at $2 / 52^{*}$ & $\begin{array}{l}1 \cdot 43(0 \cdot 8) \\
p<0 \cdot(0) 2\end{array}$ \\
\hline $\mathrm{BCG}$ in terminal ileum at $2 / 52 *$ & $\begin{array}{l}1 \cdot 2(0 \cdot 8) \\
p<0 \cdot(x) 1\end{array}$ \\
\hline $\mathrm{BCG}$ in terminal ileum at $5 / 52+$ & $\begin{array}{l}2 \cdot 3(0 \cdot 5) \\
\mathrm{p}<0 \cdot(0) 5\end{array}$ \\
\hline Irradiated $\mathrm{BCG}$ ascending colon $5 / 52^{*}$ & $\begin{array}{l}1.97(0) \cdot 4) \\
p<0 \cdot(0) 1\end{array}$ \\
\hline Irradiated BCG terminal ileum $5 / 52+$ & $\begin{array}{l}3 \cdot()(0 \cdot 2) \\
\mathrm{p}<0 \cdot()(0) 1\end{array}$ \\
\hline Irradiated BCG terminal ileum $2 / 52 \dagger$ & $\begin{array}{l}2 \cdot 3(0 \cdot 6) \\
p<(0 \cdot()() 1\end{array}$ \\
\hline Irradiated $M$ Le'prae ascending colon $5 / 52 *$ & $\begin{array}{l}0.73(0.5) \\
p<0 .(0.5\end{array}$ \\
\hline Irradiated $M$ leprae terminal ileum $5 / 52 *$ & $\begin{array}{l}1 \cdot 06(0 \cdot 6) \\
p<0 \cdot() 1\end{array}$ \\
\hline $\begin{array}{l}\mathrm{N} \text {-Saline terminal ileum } 2 / 52 \dagger \\
\mathrm{N} \text {-Saline terminal ileum } 5 / 52 \dagger\end{array}$ & $\begin{array}{l}0 \cdot(025(0 \cdot 04) \\
0 \cdot(075(0 \cdot 13)\end{array}$ \\
\hline
\end{tabular}

$\mathrm{p}=$ Comparison with normal values at same time integer using Student $s$ t test: *Standard deviations of groups of 12 animals; tStandard deviations of groups of six animals. 
Table 2 Mean visceral lymph node weights ( $m g$ ) (SD)

\begin{tabular}{|c|c|c|}
\hline & $\begin{array}{l}\text { lleocolic lymph } \\
\text { node }\end{array}$ & $\begin{array}{l}\text { Caecal lymph } \\
\text { node }\end{array}$ \\
\hline BCG at $2 / 52$ in ascending colon* & $\begin{array}{l}137 \cdot 3(66) \\
\mathrm{p}<0 \cdot 01\end{array}$ & $\begin{array}{l}142 \cdot 6(46) \\
\text { NS }\end{array}$ \\
\hline BCG at $2 / 52$ in terminal ileum* & $\begin{array}{l}82 \cdot 3(30) \\
\text { NS }\end{array}$ & $\begin{array}{l}207(59) \\
p<0.001\end{array}$ \\
\hline BCG at $5 / 52$ in terminal ileum $\dagger$ & $\begin{array}{l}117 \cdot 8(21) \\
\text { NS }\end{array}$ & $\begin{array}{l}226 \cdot 5(93) \\
\text { NS }\end{array}$ \\
\hline $\begin{array}{l}\text { Irradiated BCG } 5 / 52 \text { ascending } \\
\text { colon* }\end{array}$ & $\begin{array}{l}223 \cdot 7(128) \\
\text { NS }\end{array}$ & $\begin{array}{l}318 \cdot 1(144) \\
\text { NS }\end{array}$ \\
\hline $\begin{array}{l}\text { Irradiated BCG 5/52 terminal } \\
\text { ileum } \dagger\end{array}$ & $\begin{array}{l}265 \cdot 8(212) \\
\text { NS }\end{array}$ & $\begin{array}{l}648 \cdot 8(233) \\
p<0 \cdot 01\end{array}$ \\
\hline $\begin{array}{l}\text { Irradiated BCG 2/52 terminal } \\
\text { ileum } \dagger\end{array}$ & $\begin{array}{l}101 \cdot 1(23) \\
\mathrm{p}<0.05\end{array}$ & $\begin{array}{l}288 \cdot 6(102) \\
p<0 \cdot 01\end{array}$ \\
\hline $\begin{array}{l}\text { Irradiated } M \text { leprae } 5 / 52 \text { ascending } \\
\text { colon* }\end{array}$ & $\begin{array}{l}159 \cdot 1(51) \\
\mathrm{p}<0.02\end{array}$ & $\begin{array}{l}275(87) \\
p<0.02\end{array}$ \\
\hline $\begin{array}{l}\text { Irradiated } M \text { Leprae } 5 / 52 \text { terminal } \\
\text { ileum* }\end{array}$ & $\begin{array}{l}130.6(25) \\
\mathrm{p}<0.05\end{array}$ & $\begin{array}{l}271 \cdot 6(73) \\
p<0 \cdot 02\end{array}$ \\
\hline $\mathrm{N}$-Saline $2 / 52$ terminal ileum $\dagger$ & $91(4)$ & $114(20)$ \\
\hline $\mathrm{N}$-Saline $5 / 52$ terminal ileum $\dagger$ & $125(31)$ & $208(64)$ \\
\hline
\end{tabular}

$\mathrm{p}=$ Comparison with normal values at same time integer using Student's $t$ test; NS=Not significant; *Standard deviations of groups of 12 animals; †Standard deviations of groups of six animals.

Inoculation with irradiated BCG yielded a significant response at both sites and time integers $p<0 \cdot 001$, which was significantly greater at five weeks $p<0.001$ and more pronounced in those inoculated in the terminal ileum than the ascending colon $\mathrm{p}<0.002$. Animals inoculated with irradiated $M$ leprae in the terminal ileum or ascending colon showed a much smaller, but still significant, response at $5 / 52 \mathrm{p}<0 \cdot 01$ and $\mathrm{p}<0.05$ respectively.

\section{LYMPH NODE WEIGHTS}

These findings are given in Table 2. In live BCG inoculated animals the draining lymph node weights were significantly raised at two weeks after inoculation in the ascending colon and terminal ileum, $\mathrm{p}<0.005$ and $\mathrm{p}<0.001$ respectively. This effect had, however, disappeared by five weeks. Animals inoculated with irradiated BCG at either site showed a non significant increase in the draining lymph node weight at both two and five weeks. Animals inoculated with irradiated $M$ leprae showed a significant increase in both ileocolic and caecal node weights at $5 / 52$.

GRANULOMATOUS INFILTRATION AT THE INOCULATION SITE, MEASURED BY PLANIMETRY Granulomatous infiltration expressed as a percentage of the representative histological section area is given in Table 3. At two weeks animals inoculated with live BCG showed a significant $(\mathrm{p}<0.005)$ difference in the degree of infiltration at the two inoculation sites, the ascending colon being much more heavily infiltrated than the terminal ileum. Infiltration in the terminal ileum was past its peak at five weeks though not significantly less than at two weeks. A similar pattern was seen in the animals inoculated with irradiated BCG; infiltration continued to increase between two and five weeks in the terminal ileum though the difference was not statistically significant. There was no significant difference between the infiltration at the two inoculation sites in the case of irradiated $M$ leprae. No granulomas were seen in the liver or spleen sections from any animal.

\section{ULCERATION}

Ulceration of the bowel mucosa overlaying the inoculated Peyer's patch, but nowhere else, was seen microscopically in some animals in all the groups, apart from the control animals. It occurred in $50 \%$ of the animals inoculated with live BCG in the ascending colon and in $27 \%$ inoculated with $M$ leprae at the same site. Otherwise ulceration was seen only occasionally.

\section{LYMPH NODE INFILTRATION}

Granulomatous infiltration expressed as a percentage of the representative histological section area is given in Table 3. Infiltration was present in all cases in both ileocolic and caecal lymph nodes, apart from the control group, and was always at its greatest in the node immediately draining the inoculation site. There was no significant difference between the infiltration of the immediately draining node for any given organism, inoculation site, or time integer.

Table 3 Bowel and lymph node infiltration as percentage of representative field and total histological section respectively (SD) measured by planimetry

\begin{tabular}{|c|c|c|c|}
\hline & $\begin{array}{l}\text { Bowel } \\
\text { infiltration }\end{array}$ & $\begin{array}{l}\text { lleocolic } \\
\text { lymph node } \\
\text { infiltration }\end{array}$ & $\begin{array}{l}\text { Caecal } \\
\text { lymph } \\
\text { node } \\
\text { infiltration }\end{array}$ \\
\hline BCG ascending colon $2 / 52^{*}$ & $40 \cdot 5(15)$ & $36 \cdot 1(12)$ & $28 \cdot 2(14)$ \\
\hline BCG terminal ileum $2 / 52^{*}$ & $21 \cdot 5(14)$ & $16(15)$ & $24.4(13)$ \\
\hline BCG terminal ileum $5 / 52 \dagger$ & $6 \cdot 23(4)$ & $13 \cdot 2(13)$ & $13 \cdot 7(5)$ \\
\hline $\begin{array}{l}\text { Irradiated BCG ascending } \\
\text { colon } 5 / 52^{*}\end{array}$ & $44 \cdot 7$ (19) & $41 \cdot 3(28)$ & $16 \cdot 9(13)$ \\
\hline $\begin{array}{l}\text { Irradiated BCG terminal } \\
\text { ileum } 5 / 52 \dagger\end{array}$ & $34 \cdot 1(31)$ & $55 \cdot 9(42)$ & $73 \cdot 2(24)$ \\
\hline $\begin{array}{l}\text { Irradiated BCG terminal } \\
\text { ileum } 2 / 52 \dagger\end{array}$ & $28 \cdot 4(14)$ & $32 \cdot 1(28)$ & $66 \cdot 9(20)$ \\
\hline $\begin{array}{l}\text { Irradiated } M \text { leprae } \\
\quad \text { ascending colon } 5 / 52^{*}\end{array}$ & $39 \cdot 7(17)$ & $43 \cdot 6(26)$ & $34 \cdot 6(23)$ \\
\hline $\begin{array}{l}\text { Irradiated } M \text { leprae } \\
\quad \text { terminal ileum } 5 / 52^{*}\end{array}$ & $36 \cdot 9(7)$ & $33 \cdot 5(10)$ & $62 \cdot 5(14)$ \\
\hline
\end{tabular}

*Standard deviation of groups of 12 animals; +Standard deviation of groups of six animals. 


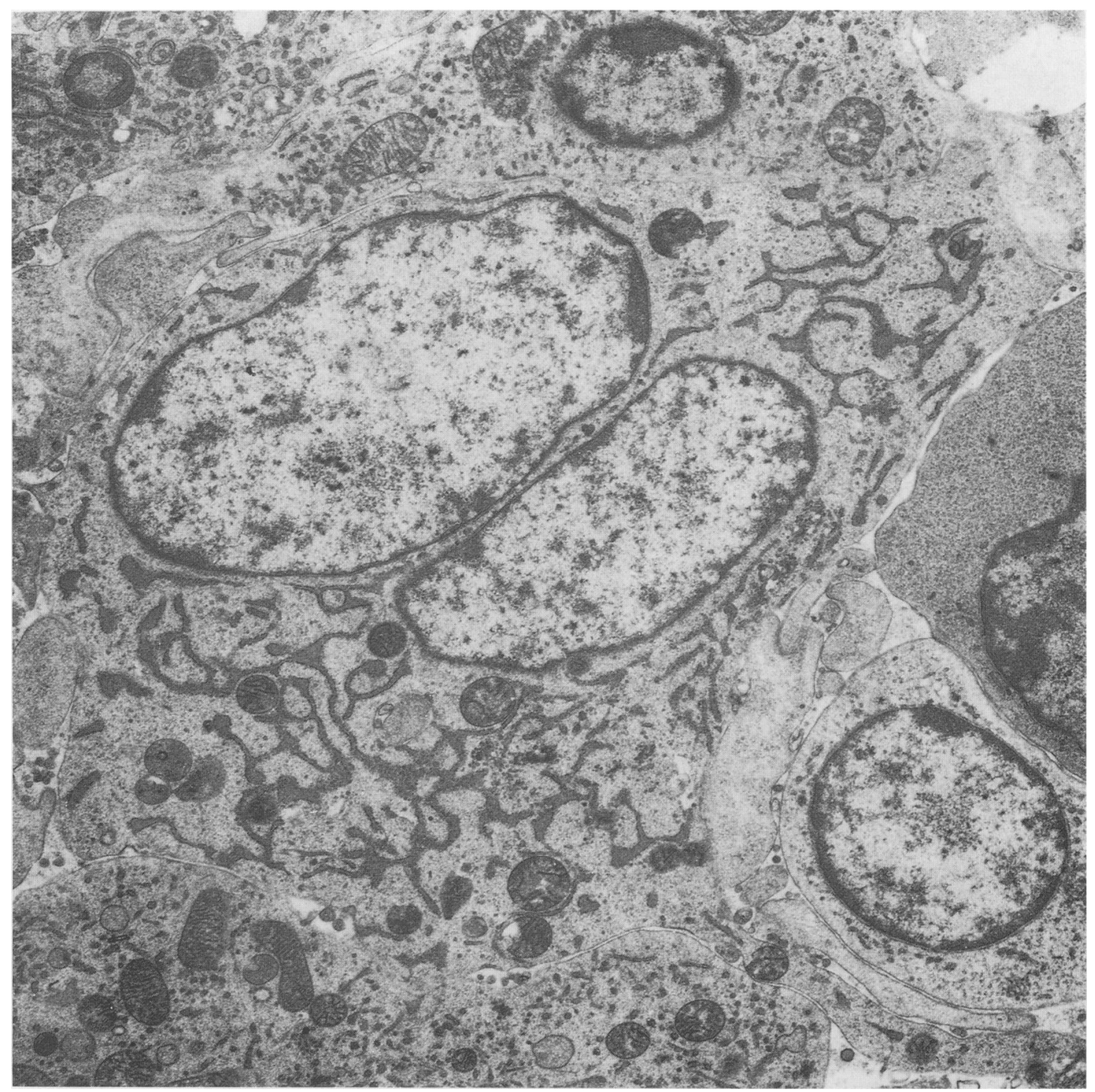

Fig. 2 Electronmicrograph of epithelioid cell from granuloma induced $2 / 52$ after inoculation of terminal ileum with live $B C G$ (Pasteur). $\times 7500$.

ZIEHI. NEELSON STAINING

Examination of Ziehl Neelson stained sections showed that with a single exception all bowel sections from animals inoculated with live BCG in the ascending colon showed the presence of acid fast bacilli at this site. Conversely, only one animal inoculated with live $\mathrm{BCG}$ in the terminal ileum showed the presence of acid fast bacilli. The only other positive findings were the bowel sections of one of 12 animals inocula- ted with irradiated $M$ leprae in the ascending colon at five weeks and in one of the immediately draining lymph nodes of these animals.

ELECTRON MICROSCOPY

Ultrastructurally the granulomatous tissue from live BCG inoculated animals revealed the presence of epithelioid cells, characterised by the presence of prominent large nuclei and endoplasmic reticulum in 


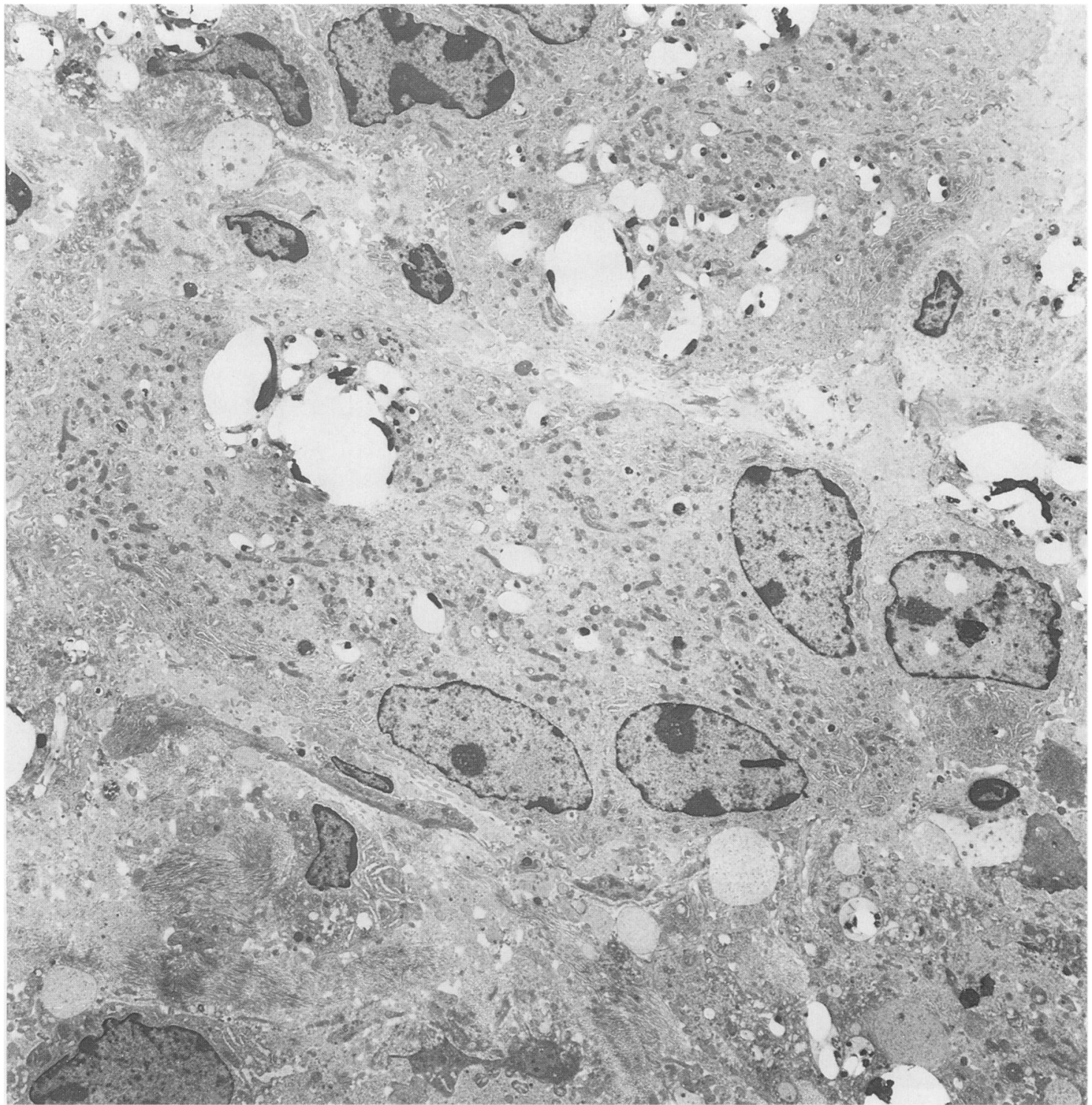

Fig. 3 Electronmicrograph of macrophage infiltration 5/52 after inoculation of terminal ileum with irradiated $\mathrm{M}$ leprac. $\times 3000$.

a cytoplasm otherwise largely devoid of organelles. Few acid fast bacilli were seen in either bowel or lymph node tissues (Fig. 2). Anituals inoculated with irradiated BCG show the presence of a lesser number of epithelioid cells with similar characteristics. Fibroblasts with collagen deposition, however, were prominent. Tissue from animals inoculated with irradiated $M$ leprae shows an infiltration of macrophages containing phagocytosed bacilli and cytoplasmic vacuoles (Fig. 3).

\section{Discussion}

This work shows that it is possible to produce a simple animal model of granulomatous infiltration in the bowel wall. Early attempts to achieve this were based upon the lymphoedema resulting from the direct inoculation of sclerosing reagents into the lymphatics draining the bowel' or on the piezo electric effect of finely divided silica materials administered by enteral feeding." A reproducible model of an hacmorrhagic 
colitis has been induced in a number of animal species by the feeding of a carrageenan extract of seaweed. ${ }^{3}$ The resulting ulceration of the caecum, colon, and rectum bears some resemblance to ulcerative colitis in man, but it is noteworthy that patients receiving a regular intake of degraded carrageenan in the course of treatment for peptic ulcer disease show no increased incidence of inflammatory bowel disease. ${ }^{16}$

Homogenates of human Crohn's disease tissue inoculated into the rabbit ileum, after a prolonged period, in some cases, show changes in the bowel wall not dissimilar to Crohn's disease. ${ }^{+}$This effect was destroyed when the homogenates were exposed to cobalt irradiation (2.5 MR) or passed through a 25 $\mu \mathrm{m}$ filter, thereby suggesting the presence of a viable and transmissible aetiological agent. Efforts to reproduce this work, however, have met with mixed success. ${ }^{5 n}$

No information has hitherto been available regarding the results of direct inoculation of measured amounts of known mycobacteria into the bowel wall. It is relevant that among the many different factors that have been considered in relation to the aetiology of inflammatory bowel disease the role of a possible mycobacterial infection has received much attention. Thus Burnham et al ${ }^{x}$ isolated what were thought to be cell wall defective forms of mycobacteria from biopsy material of cases of inflammatory bowel disease and White $e t$ a $l^{17}$ using an ELISA technique were able to show increased levels of antimycobacterial antibodies in the sera of patients from whom they had isolated cell wall deficient organisms. Cheodini and Van Kruningen ${ }^{7}$ isolated from two patients with Crohn's disease a previously unrecognised acid fast mycobactin dependent mycobacterium, which was considered to be most closely related to mycobacterium paratuberculosis. A seven day old goat fed orally $50 \mathrm{mg}$ of this organism developed granulomatous disease of its small intestine with the presence of small non-caseating tuberculoid granulomas at five months. Similarly Graham et al isolated cell wall defective forms of mycobacteria from 12 patients with Crohn's disease and three with ulcerative colitis; none was isolated from control samples. It is thus possible that mycobacteria not readily able to be cultivated with present techniques or that remnants from previous mycobacterial infection may play an important role in the aetiology of inflammatory bowel disease.

In our present study it is of interest that using live BCG the degree of granulomatous infiltration induced in the bowel varies so markedly depending upon whether the small or large bowel is involved. This was an unexpected but consistent finding. The mechanism underlying this is obscure but it is in keeping with the findings of Morson et al ${ }^{1 \mathrm{~s}}$ who noted that the number of granulomas seen in a series of patients with Crohn's disease affecting either the terminal ileum or colon was always greater in the latter.

The differences seen in Ziehl Neelson staining are also relevant in this context. Acid fast bacilli are not a feature of Ziehl Neelson staining of Crohn's disease tissue and this has been used as an argument against their involvement in the aetiology of the condition. Our findings indicate that different areas of the bowel may handle mycobacteria differently and that even after the relatively short time integers used in this study AFB may not be readily identified in mycobacteria induced granulomatous infiltrates. In this context it is of interest to note that Butcher et al ${ }^{19}$ described their negative findings after the use of cloned antimycobacterial DNA probes on human Crohn's disease tissues. In the absence of detectable DNA sequences using these sensitive and specific techniques they concluded that if mycobacteria are involved in the aetiology of Crohn's disease they either do not persist in diseased tissue or are present at a level of less than one mycobacterium per ten cells. Our findings show a further similarity to Crohn's disease in that although the inoculum was placed subserosally the majority of the resultant granulomatous infiltration occurred in the Peyer's patch and spread outwards into the surrounding submucosa. This is noted to be characteristic of Crohn's disease. ." Moreover when ulceration occurred it was only in the mucosa overlaying the Peyer's patch and in this regard it is of interest that Hadfield in $1939^{21}$ noted a preponderance of ulceration in this region and postulated that it was due to pressure from the enlarging patch. In our study ulceration was most common in animals inoculated in the large bowel but not always in those with the most extensive bowel infiltration. Fissuring and true 'cobblestoning' of the bowel mucosa were not seen. This may be related to the relatively short time span of our study. We note that skin reactions to purified protein derivative were present after inoculation with live and irradiated BCG with a lesser response after the inoculation of irradiated $M$ leprae. This is in contrast with previous work " which showed a greater skin test response with the same dose of purified protein derivative, to live BCG and irradiated $M$ leprae at similar doses and time integers when inoculated into the guinea pig ear. It is of interest that patients with Crohn's disease have in some studies, ${ }^{2-24}$ but not in others, ${ }^{25}$ been shown to possess a defect of delayed cutaneous sensitivity on the basis of skin testing with purified protein derivative. Our findings from this study suggest that the presence of mycobacteria within the bowel wall may not give rise to the expected degree of delayed cutaneous sensitivity. The consistent and 
reproducible animal experimental model we have described has enabled us to study the effects of a variety of immunomodulating agents on these mycobacteria induced granulomatous lesions. In the light of the findings of Cheodini and Van Kruningen, Burnham et al, ${ }^{8}$ White et al, ${ }^{17}$ and Graham et al $l^{4}$ it might be considered relevant to apply this technique to the study of the histological and cutaneous responses accruing from the inoculation of the principal strains of Mycobacterium paratuberculosis as well as investigating the effects of filtrates prepared from the granulomatous bowel and lymph node tissues of the present study.

The authors wish to thank Miss M Jacques, Mr S Gschmeissner, Mr F Schindler and Mr P Papasavva for their excellent technical assistance, and Mrs J Saxby for typing the manuscript. They also gratefully acknowledge the financial support of the Lilian May Coleman Fund of the Royal College of Surgeons of England.

\section{References}

1 Reichart FL, Mathes ME. Experimental lymphocdema of the intestinal tract and its relationship to regional cicatrizing enteritis. Ann Surg 1936; 104: 601-16.

2 Chess S, Chess D, Orlander G, Benner W, Cole WH. Production of chronic enteritis and other systemic lesions by ingestion of fincly divided foreign materials. Surgery 1950; 27: 221-34.

3 Marcus R, Watt J. Seaweeds and ulcerative colitis in laboratory animals. Lancet 1969; ii: 489-90.

4 Cave DR, Mitchell DN, Brooke BN. Experimental animal studies of the aetiology and pathogenesis of Crohn's disease. Gastroenterology 1975; 69: 618-24.

5 Simonowitz D, Bloch GE, Riddell RH, Craft SC, Kirsner JB. The production of an unusual tissue reaction in rabbit bowel injected with Crohn's disease homogenates. Surgery 1977; 82: 211-8.

6 Bolton PH, Owen E, Healtey RV, Jones Williams W, Hughes LE. Negative findings in laboratory animals for a transmissible agent in Crohn's disease. Lancet 1973; ii: $1222-4$.

7 Chiodine RJ, Van Kruningen J, Thayer WR, Merkal RJ, Coutu JA. Possible role of mycobacteria in inflammatory bowel disease. Dig Dis Sci 1984; 29: 1073-9.

8 Burnham WR, Leonard-Jones JC, Stanford JL, Bird RJ. Mycobacteria as a possible cause of inflammatory bowel disease. Lancet 1978; ii: 693-6.
9 Graham DY, Marhesich DC, Yashimura HH. Mycobacteria and inflammatory bowel discase. Results of culture. Gastroenterology 1987; 92: 436-42.

10 Narayanan RB, Badenoch Jones P. Turk JL. Experimental mycobacterial granulomas in guinea pig lymph nodes: ultrastructural observations. J Pathol 1981; 134: 253-65.

11 Narayanan RB, Badenoch-Jones P, Curtis J, Turk JL. Comparison of mycobacterial granulomas in guinca pig lymph nodes. J Pathol 1982; 138: 219-33.

12 Miles AA. Misra SS. The estimation of bactericidal power of the blood. J Hyg 1938; 38: 732.

13 Hart PD, Rees RJW. Effect of macrocyclon on acute and chronic pulmonary tuberculosis infection in mice as shown by viable and total bacterial counts. Br J Exp Pathol 1960; 41: 414-21.

14 Mchra V, Bloom B. Induction of cell mediated immunity to M Leprae in guinca pigs. Infect Immun 1979; 23: 787-94.

15 Dwyer JM, Parker D, Turk JL. Suppression of delayed hypersensitivity to tuberculin by antigenic competition: a positive immunoregulatory mechanism sensitive to cyclophosphamide. Immunology 1981; 42: 549-59.

16 Bonfils S. Carrageenan and the human gut. Lancet 1970; ii: 414 .

17 White SA. In: Recent advances in Crohn's disease 198I. Procecdings of the International Workshop on Crohn's Disease. Noardwijk, 24-28 June 1980. The Haguc. Martinius Nyhoff.

18 Chambers TJ, Marson BJ. The relationship between the course of Crohn's disease and the number of granulomas in the involved bowel. Proc VIII International Conference on Sarcoidosis and other Granulomatous Diseases. In: Jones-Williams W, Davies BM, cds. Cardiff: Alpha Omega, 1980: 750-7.

19 Butcher PD, Thompson J, Herman Taylor J, McFadden JJ. The use of cloned mycobacterial DNA probes for the detection of mycobacteria in Crohn's disease tissuc. Biochem Soc Trans 1987; 15: 549-50.

20 Jones-Williams W. Histology of Crohn's syndrome. Gut 1964; 5: 510-6.

21 Hadfield G. The primary histopathological lesion of regional enteritis. Lancet 1939; ii: 733-5.

22 Blackburn G, Hadfield G, Hunt AH. St Bartholomew's Hospital Review 1939: 181.

23 Phear DN. The relation between regional enteritis and sarcoidosis. Lancet 1958; ii: 1250-1.

24 Williams WJ. A study of Crohn's syndrome using tissue extracts and the Kveim and Mantoux tests. Gut 1965; 6: 503.

25 Fletcher J, Hinton M. Tuberculin sensitivity in Crohn's disease. Lancet 1967; ii: 753-4. 